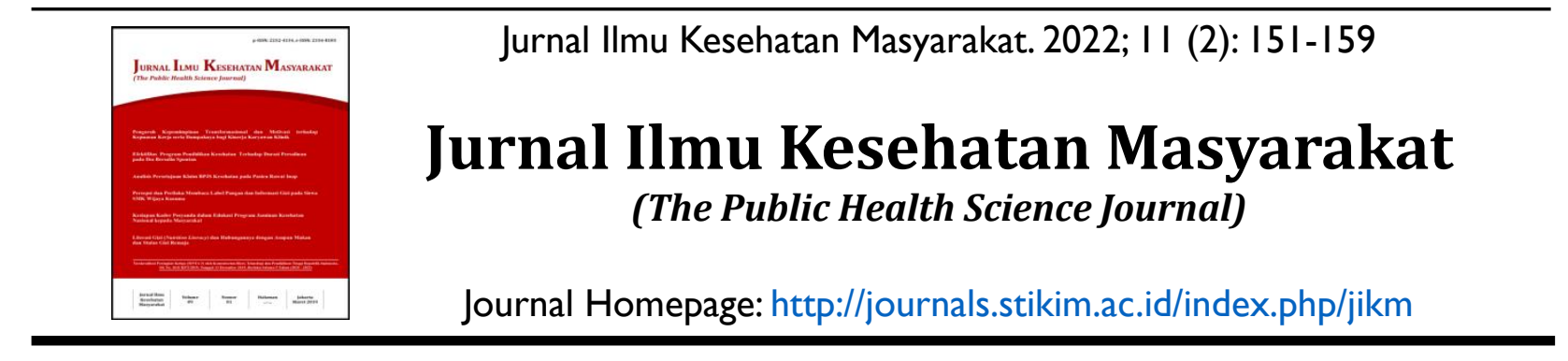

\title{
Faktor Tidak Langsung Penyebab Kejadian Bayi Berat Lahir Rendah (BBLR)
}

\author{
Wiwik Eko Pertiwi ${ }^{1 *}$, Annissa ${ }^{2}$, Feling Polwandari ${ }^{3}$ \\ ${ }^{1,2}$ Program Studi Kesehatan Masyarakat, Universitas Faletehan \\ ${ }^{3}$ Program Studi Sarjana dan Profesi Kebidanan, Universitas Faletehan
}

\begin{abstract}
Abstrak
Prevalensi Bayi Berat Lahir Rendah (BBLR) berdasarkan hasil Riskesdas tahun 2018 sebanyak 6,2\% dan angka ini mengalami kenaikan dari tahun 2013. Tahun 2018 kasus BBLR di Provinsi Banten menempati urutan 9 besar dari 34 Provinsi yang ada di Indonesia. Pada tahun 2018 berdasarkan Profil Kesehatan Dinas Kesehatan Kota Cilegon, menunjukkan persentase BBLR di Kecamatan Cilegon mencapai 4,2\% (38 kasus) dari 91 I jumlah kelahiran hidup. Penelitian ini bertujuan untuk mengetahui faktor tidak langsung penyebab kejadian BBLR di Kota Cilegon dengan menggunakan metode penelitian kasus kontrol dengan sampel sebanyak 108 responden yang terdiri dari 54 kelompok kasus dan 54 kelompok kontrol. Lokasi penelitian adalah wilayah kerja Puskesmas Cilegon dan Citangkil Kota Cilegon, Banten. Pengumpulan data menggunakan kuesioner dengan metode wawancara dan buku KIA responden. Data dianalisis secara univariat dan bivariat (chi-square). Hasil penelitian menunjukan bahwa tidak ada hubungan antara faktor predisposisi (status sosial ekonomi, budaya dan tingkat pendidikan), faktor enabling (ketersediaan pelayanan kesehatan, jarak pelayanan kesehatan, keterpaparan media promosi kesehatan) dan faktor reinforcing (dukungan keluarga dan peran petugas kesehatan) dengan kejadian BBLR. Edukasi kesehatan ibu hamil dapat ditingkatkan melalui penggunaan media-media elektronik misal melalui grup WA, instagram dan media sosial lainnya.
\end{abstract}

Kata Kunci: BBLR, sosial ekonomi, budaya, keterpaparan media, dukungan keluarga.

\begin{abstract}
Prevalence of LBW based on the results of Riskesdas in 2018 was $6.2 \%$ and increased from 2013. In 2018 the case of LBW in Banten Province ranks 9th out of 34 Provinces in Indonesia. In 2018, based on the Health Profile of the Cilegon City Health Office, it shows that the percentage of LBW in Cilegon District reached 4.2\% (38 cases) of 91 I live births. This study aims to determine indirect factors that caused of infant incidence. This research using the case control research method with a sample of 108 respondents consisting of 54 case groups and 54 control groups. The research locations being the working areas of the Cilegon and Citangkil Health Centers, Cilegon City. Collecting data using a questionnaire with the interview method and the respondent's KIA book. Data were analyzed by univariate and bivariate (chi-square). There was no significant relationship between predisposition factor (socio-economic status, culture and level of education), enabling factor (availability of health services, distance of health services, exprosure of health promotion media) and reinforcing factor (family support and role of health workers) with the incidence of LBW. Health education for pregnant women can be improved through the use of electronic media, for example through the WA group, Instagram and other social media.
\end{abstract}

Keywords: LBW, socio-economic, culture, exprosure of health promotion media, family support.

Korespondensi*: Wiwik Eko Pertiwi, Departemen Kesehatan Masyarakat, Universitas Faletehan, Jl. Raya Cilegon km. 06, Kramatwatu, Serang, Banten, E-mail:wiek.ep@gmail.com, No.Telp: +628777I I67746 


\section{Pendahuluan}

Angka Kematian Bayi (AKB) merupakan salah satu indikator keberhasilan program pembangunan kesehatan pada bayi. Berdasarkan Survey Demografi dan Kesehatan Indonesia (SDKI) tahun 2017, angka kematian bayi mengalami penurunan jika dibandingkan dengan SDKI tahun 2012, dari 29 menjadi 24 kasus kematian per 1.000 kelahiran hidup. ${ }^{1}$ Meskipun terjadi penurunan, namun angka ini masih relatif tinggi. Pada tahun 2017, Angka kematian neonatal di Indonesia masih tinggi yaitu sebanyak 15 kasus per 1.000 kelahiran hidup. Dengan angka kematian ini, Indonesia menjadi salah satu negara dengan angka kematian neonatal tertinggi di dunia. ${ }^{2}$

$$
\text { Angka kematian bayi dapat }
$$
disebabkan oleh banyak faktor, salah satunya adalah Bayi Berat Lahir Rendah (BBLR). Riset menyebutkan bahwa BBLR merupakan salah satu faktor yang secara signifikan berpengaruh terhadap kejadian kematian bayi. ${ }^{3}$ Data World Health Organization (WHO) mencatat Indonesia berada di peringkat sembilan dunia dengan persentase BBLR lebih dari $15,5 \%$ dari kelahiran bayi setiap tahunnya. ${ }^{4}$ Tingginya angka kelahiran BBLR di Indonesia salah satunya disebabkan masih kurangnya asupan gizi yang mencukupi pada janin dan ibu. Selain itu, aktivitas ibu yang padat berpotensi meningkatkan stres. ${ }^{3}$

Data statistik menunjukkan bahwa BBLR menjadi salah satu penyebab utama terjadinya kesakitan dan kematian pada neonatus di negara berkembang. Kondisi inilah yang menyebabkan angka kesakitan dan kematian pada nenonatus di negara berkembang masih tinggi. ${ }^{4}$ Bayi Baru Lahir (BBL) dikatakan normal apabila memiliki berat badan rata-rata 3,2 Kilogram dengan usia gestasi 37-41 minggu. Oleh karena itu, salah satu indikator kesehatan BBL adalah berat badan. Pada umumnya, bayi yang memiliki berat lahir kurang dari normal mempunyai tingkat resiko mengalami masalah atau komplikasi pada saat lahir yang lebih tinggi. ${ }^{5}$ Rendahnya berat badan
BBL dipengaruhi oleh faktor langsung dan tidak langsung. Faktor langsung penyebab BBLR diantaranya faktor ibu dan faktor janin. Faktor bayi yang dapat menjadi penyebab BBLR diantaranya adalah cacat bawaan dan infeksi selama dalam kandungan serta kelainan plasenta. ${ }^{6,7}$ Faktor ibu yang secara signifikan menyebabkan BBLR diantaranya adalah usia (>35 tahun), jarak kelahiran, riwayat BBLR sebelumnya, adanya penyakit kronis yang diderita oleh ibu serta faktor sosial ekonomi (sosial ekonomi rendah, pekerjaan fisik yang berat, kurangnya pemeriksaan kehamilan, kehamilan yang tidak dikehendaki), serta faktor lain diantaranya adalah komplikasi kehamilan. $^{8,9}$

Faktor tidak langsung yang diperkirakan menjadi penyebab BBLR diantaranya adalah pendidikan keluarga, sosial ekonomi, faktor budaya terutama masih ada kepercayaan untuk melarang memakan makanan tertentu dan faktor fasilitas kesehatan. Analisis hubungan dari penelitian sebelumnya menunjukkan bahwa kejadian BBLR berkorelasi secara signifikan dengan usia kehamilan, tingkat pendidikan, riwayat komplikasi dan riwayat Antenal Care (ANC). ${ }^{10}$

Tingkat pendidikan ibu hamil juga merupakan faktor kejadian BBLR karena pendidikan dikaitkan dengan tingkat pengetahuan seseorang. Hasil penelitian menunjukkan bahwa tingkat pengetahuan ibu berhubungan secara signifikan dengan kejadian BBLR. Ibu yang tingkat pengetahuan yang rendah terhadap status gizi selama hamil, akan berdampak kepada asupan makanan dan beresiko terhadap kejadian BBLR. ${ }^{11}$

Aspek sosial budaya khususnya budaya pantangan mengonsumsi makananmakanan tertentu selama hamil juga sangat mempengaruhi status gizi ibu hamil sehingga akan berpotensi terhadap resiko BBLR. Selama masa kehamilan, apabila ibu hamil meyakini dan menganut kepercayaan bahwa mengkonsumsi makanan tertentu dapat berdampak pada kesehatan bayi yang dikandungnya maka hal ini dapat 
berpengaruh terhadap berat bayi yang akan dilahirkannya. Hal ini didukung oleh penelitian sebelumnya yang menyebutkan bahwa kebiasaan makan berhubungan secara signifikan dengan BBLR. ${ }^{12}$

Tahun 2018 kasus BBLR di Provinsi Banten menempati urutan 9 besar dari 34 Provinsi yang ada di Indonesia. Berdasarkan data tersebut perkembangan kasus bayi dengan BBLR dari tahun 2007 sampai 2018 secara umum terjadi peningkatan, dan BBLR merupakan tujuan indikator Kementerian Kesehatan dalam peningkatan status kesehatan masyarakat yaitu menurunnya persentase BBLR dari 10,2\% menjadi $8 \% .^{12}$ Kota Cilegon merupakan salah satu Kota di Propinsi Banten yang berupaya untuk menurunkan Angka Kematian Ibu dan neonatal sebesar 25\% dengan tingkat kejadian BBLR paling tinggi. Pada tahun 2018 berdasarkan Profil Kesehatan Dinas Kesehatan Kota Cilegon, menunjukkan persentase BBLR di Kecamatan Cilegon mencapai 4,2\% (38 kasus) dari 911 jumlah kelahiran hidup. ${ }^{13}$

Pada penelitian-penelitian sebelumnya lebih banyak menganalisis dan mengeksplorasi faktor-faktor yang merupakan penyebab langsung kejadian BBLR. Berdasar dari penelitian-penelitian yang ada sebelumnya maka penelitian ini lebih banyak menganalisis faktor-faktor tidak langsung kejadian BBLR. Penelitian ini dapat menjadi salah satu referensi yang terkait dengan faktor-faktor tidak langsung terhadap kejadian BBLR mengingat kurangnya penelitian dengan tema tersebut. Beberapa hasil penelitian menunjukan bahwa kejadian BBLR tidak hanya disebabkan oleh faktor ibu dan bayi saja, namun juga dapat disebabkan karena faktor lain atau faktor tidak langsung. Oleh karena itu, penelitian ini bertujuan untuk mengetahui faktor tidak langsung penyebab kejadian Bayi Berat Lahir Rendah di Kota Cilegon Tahun 2020.

\section{Metode}

Penelitian ini bersifat analitik dengan pendekatan case control. Penelitian dilakukan untuk mengetahui hubungan antara faktor predisposisi (status sosial ekonomi, budaya dan tingkat pendidikan), faktor enabling (ketersediaan pelayanan kesehatan, jarak pelayanan kesehatan, keterpaparan media promosi kesehatan) dan faktor reinforcing (dukungan keluarga, peran petugas kesehatan) dengan kejadian BBLR di wilayah kerja Puskesmas Cilegon dan Citangkil Kota Cilegon tahun 2020. Penelitian dilaksanakan di wilayah kerja Puskesmas Cilegon dan Citangkil Kota Cilegon pada bulan Maret sampai Agustus 2020.

Populasi dalam penelitian ini adalah ibu yang melahirkan bayi BBLR tahun 2019 di Puskesmas Cilegon dan Puskesmas Citangkil, sehingga total populasi dalam penelitian ini sebanyak 54 orang. Sampel dalam penelitian ini adalah sebanyak 108 orang yang terdiri dari 54 orang sebagai kelompok kasus dan 54 orang kelompok kontrol. Kriteria inklusi sampel adalah sebagai berikut:

1. Ibu yang tinggal di wilayah kerja Puskesmas Cilegon dan Citangkil Kota Cilegon.

2. Ibu yang melahirkan bayi dengan berat lahir rendah pada tahun 2019 .

3. Ibu yang tercatat dalam buku register kehamilan di Puskesmas Cilegon dan Citangkil Kota Cilegon.

4. Ibu bersedia dijadikan sebagai responden penelitian.

Sampel kontrol adalah ibu yang melahirkan bayi dengan Berat Badan Lahir Normal (BBLN) hidup pada periode bulan Januari sampai Desember 2019 dan jumlah disamakan dengan ibu yang melahirkan BBLR, dengan kriteria inklusi sebagai berikut:

1. Ibu yang tinggal di wilayah kerja Puskesmas Cilegon dan Citangkil Kota Cilegon.

2. Ibu yang tercatat dalam buku register ibu di wilayah kerja Puskesmas Cilegon dan Citangkil Kota Cilegon.

3. Ibu yang melahirkan bayi dengan Berat Badan Lahir Normal tahun 2019.

4. Ibu bersedia dijadikan sebagai responden 
penelitian.

Data yang digunakan dalam penelitian ini adalah data primer dan sekunder. Data primer yang dikumpulkan berupa data yang terkait faktor predisposisi (status sosial ekonomi, budaya dan tingkat pendidikan), faktor enabling (ketersediaan pelayanan kesehatan, jarak pelayanan kesehatan, keterpaparan media promosi kesehatan) dan faktor reinforcing (dukungan keluarga, peran petugas kesehatan). Data primer dikumpulkan menggunakan kuesioner yang dibuat oleh peneliti merujuk pada penelitian sebelumnya dengan metode pengumpulan data melalui wawancara langsung dengan kelompok kasus dan kelompok kontrol. Sedangkan data sekunder diperoleh dari kartu ibu dan buku KIA ibu di wilayah Puskesmas Cilegon dan Citangkil Kota Cilegon dan data primer yang dilakukan dengan cara wawancara terhadap kelompok kasus dan kelompok kontrol. Data penelitian juga akan dikumpulkan dari pihak pemberi layanan kesehatan (petugas kesehatan) yang digunakan sebagai penunjang sehingga informasi yang diperoleh lebih lengkap dan komprehensif. Data penelitian dianalisis secara univariat dan bivariat menggunakan uji Chi-Square dengan batas kemaknaan $\alpha=0,05$ pada taraf kepercayaan $95 \%$.

\section{Hasil}

Tabel 1. Distribusi Frekuensi Faktor Tidak Langsung Penyebab Kejadian BBLR

\begin{tabular}{llcc}
\hline \multicolumn{1}{c}{ Variabel } & \multicolumn{1}{c}{ Kategori } & n & \% \\
\hline Sosial Ekonomi & Rendah & 108 & 99,1 \\
& Tinggi & 1 & 0,9 \\
Budaya & Mendukung & 9 & 8,3 \\
& Tidak mendukung & 99 & 91,7 \\
Tingkat Pendidikan & Rendah & 26 & 24,1 \\
& Tinggi & 82 & 75,9 \\
Ketersediaan Pelayanan Kesehatan & Tidak Tersedia & 3 & 2,8 \\
& Tersedia & 105 & 97,2 \\
Jarak Pelayanan Kesehatan & Jauh & 89 & 82,4 \\
& Dekat & 19 & 17,6 \\
Keterpaparan Media & Terpapar & 42 & 38,9 \\
& Tidak Terpapar & 66 & 61,1 \\
Dukungan Keluarga & Mendukung & 49 & 45,5 \\
& Tidak mendukung & 59 & 54,6 \\
Dukungan Petugas Kesehatan & Mendukung & 21 & 19,4 \\
& Tidak mendukung & 87 & 80,6 \\
\hline
\end{tabular}

Hasil distribusi frekuensi pada tabel 1 menjelaskan bahwa bahwa sebanyak $99,1 \%$ responden memiliki tingkat sosial ekonomi rendah, sebanyak $8,3 \%$ responden mempunyai budaya yang mendukung terjadinya kejadian BBLR, sebanyak $24,1 \%$ responden memiliki tingkat pendidikan rendah, sebanyak $2,8 \%$ responden menyatakan ketersediannya pelayanan kesehatan, sebanyak $82,4 \%$ responden menyatakan jauhnya jarak pelayanan kesehatan, sebanyak 38,9\% responden menyatakan ada keterpaparan media terkait promosi kesehatan BBLR, sebanyak 45,5\% keluarga responden mendukung adanya kejadian BBLR dan sebanyak 19,4\% menyatakan adanya dukungan petugas kesehatan terhadap kejadian BBLR.

Hasil analisis kejadian BBLR pada tabel 2 menunjukan tidak terdapat hubungan yang bermakna antara faktor sosial ekonomi, budaya, tingkat pendidikan, ketersediaan pelayanan kesehatan, jarak pelayanan kesehatan, keterpaparan media, dukungan keluarga dan peran tugas kesehatan dengan kejadian BBLR di Cilegon. 
Tabel 2. Analisis Kejadian Distribusi Frekuensi Faktor Tidak Langsung Penyebab Kejadian BBLR

\begin{tabular}{|c|c|c|c|c|c|c|}
\hline \multirow{3}{*}{ Variabel } & \multirow{3}{*}{ Kategori } & \multicolumn{4}{|c|}{ Kejadian BBLR } & \multirow{3}{*}{ Pvalue } \\
\hline & & \multicolumn{2}{|c|}{ BBLR } & \multicolumn{2}{|c|}{ Tidak BBLR } & \\
\hline & & $\mathbf{n}$ & $\%$ & $\mathbf{n}$ & $\%$ & \\
\hline \multirow[t]{2}{*}{ Sosial Ekonomi } & Rendah & 54 & 50,5 & 53 & 49,5 & 1,000 \\
\hline & Tinggi & 0 & 0,0 & 1 & 100 & \\
\hline \multirow[t]{2}{*}{ Budaya } & Mendukung & 2 & 22,2 & 7 & 77,8 & 0,161 \\
\hline & Tidak Mendukung & 52 & 52,5 & 47 & 47,5 & \\
\hline \multirow[t]{2}{*}{ Tingkat Pendidikan } & Rendah & 11 & 42,3 & 15 & 57,7 & 0,500 \\
\hline & Tinggi & 43 & 52,4 & 39 & 47,6 & \\
\hline \multirow[t]{2}{*}{ Ketersediaan Pelayanan Kesehatan } & Tidak Tersedia & 2 & 66,7 & 1 & 33,3 & 1,000 \\
\hline & Tersedia & 52 & 49,5 & 53 & 50,5 & \\
\hline \multirow[t]{2}{*}{ Jarak Pelayanan Kesehatan } & Jauh & 44 & 49,4 & 45 & 50,6 & 1,000 \\
\hline & Dekat & 10 & 52,6 & 9 & 47,4 & \\
\hline \multirow[t]{2}{*}{ Keterpaparan Media } & Terpapar & 23 & 54,8 & 19 & 45,2 & 0,554 \\
\hline & Tidak Terpapar & 31 & 47,0 & 35 & 53,0 & \\
\hline \multirow[t]{2}{*}{ Dukungan Keluarga } & Mendukung & 28 & 57,1 & 21 & 42,9 & 0,246 \\
\hline & Tidak Mendukung & 26 & 44,1 & 33 & 55,9 & \\
\hline \multirow[t]{2}{*}{ Dukungan Tugas Kesehatan } & Mendukung & 8 & 38,1 & 13 & 61,9 & 0,331 \\
\hline & Tidak Mendukung & 46 & 52,9 & 41 & 47,1 & \\
\hline
\end{tabular}

\section{Pembahasan}

Hasil penelitian menunjukkan bahwa hampir seluruh responden memiliki tingkat sosial ekonomi rendah, sebagian besar responden menyatakan bahwa tidak terdapat budaya yang mendukung terjadinya kejadian BBLR seperti diantaranya larangan mengkonsumsi ikan, udang dan buah-buahan tertentu. Rata-rata responden memiliki tingkat pendidikan SMP dan Sekolah Dasar (SD) yang berarti bahwa tingkat responden dapat digolongkan kedalam tingkat pendidikan rendah. Fasilitas pelayanan kesehatan bagi ibu hamil di lokasi penelitian tersedia dan mudah dijangkau dengan menggunakan berbagai moda transportasi darat meskipun lebih dari 50\% responden menyatakan jarak pelayanan kesehatan dari rumah tergolong jauh. Paparan informasi kesehatan khususnya tentang BBLR masih terbilang kurang, paparan informasi kesehatan lebih banyak tentang kesehatan ibu hami secara umum yang diberikan oleh petugas kesehatan terutama bidan desa dan kader. Hasil penelitian juga menunjukkan bahwa persentase keluarga yang mendukung ibu hamil untuk mengurangi resiko terjadinya BBLR dengan yang mendukung hampir seimbang. Sebanyak 45,5\% keluarga responden mendukung adanya kejadian
BBLR dan 54,5\% tidak mendukung terjadinya BBLR. Petugas kesehatan sebagai pembawa pesan kesehatan dan fasilitator kesehatan menunjukkan lebih banyak dukungan kepada ibu hamil dalam pencegahan terjadinya BBLR.

\section{Faktor Predisposisi}

Faktor predisposisi merupakan faktorfaktor yang mempermudah terbentuknya perilaku kesehatan seseorang. Faktor predisposisi pada penelitian ini terdiri dari tingkat pendidikan, status sosial ekonomi, budaya terhadap kejadian BBLR. Faktor predisposisi tersebut merupakan faktor penyebab tidak langsung terjadinya BBLR. Berdasarkan hasil penelitian menunjukkan bahwa tingkat pendidikan responden termasuk dalam kategori rendah yaitu SMP dengan tingkat pendapatan yang juga didominasi oleh pendapatan rendah. Hal ini terlihat pada distribusi frekuensi status sosial ekonomi responden yang berada pada kategori rendah. Sementara faktor predisposisi lainnya pada penelitian ini adalah aspek sosial budaya. Hasil penelitian menunjukkan bahwa sebagian besar responden yang diwawancara menyatakan bahwa tidak terdapat aspek-aspek sosial budaya yang bertentangan dengan kesehatan ibu selama proses kehamilan. 
Sebagian besar responden menyatakan bahwa tidak terdapat larangan-larangan mengkonsumsi makanan dan buah-buahan tertentu.

Hasil penelitian menunjukkan bahwa tidak terdapat hubungan yang signifikan antara tingkat pendidikan tidak berhubungan secara signifikan dengan kejadian BBLR, hal ini tidak sejalan dengan penelitian sebelumnya yang menyatakan bahwa terdapat hubungan antara pendidikan dengan kejadian BBLR. ${ }^{16}$ Pada penelitian ini, tingkat pendidikan responden didominasi oleh tingkat pendidikan rendah. Beberapa penelitian sebelumnya menunjukkan bahwa tingkat pendidikan yang dimiliki ibu mempunyai pengaruh kuat pada perilaku reproduksi, kelahiran, kematian anak dan bayi, kesakitan dan sikap serta kesadaran atas kesehatan keluarga. Latar belakang pendidikan akan mempengaruhi sikapnya dalam memilih pelayanan kesehatan dan pola konsumsi makan semasa hamil. Ibu yang berpendidikan rendah sulit untuk menerima inovasi dan sebagian besar kurang mengetahui pentingnya perawatan sebelum kelahiran. ${ }^{17}$ Ibu yang menyelesaikan pendidikan formal lebih memiliki kemampuan untuk bekerja sehingga ibu memiliki pendapatan sendiri dan mampu memberikan informasi tentang asupan gizi yang baik selama kehamilan, dan hal ini yang membuat ibu lebih sadar akan risiko lain yang dapat menyebabkan BBLR. ${ }^{18,19}$

Sosial ekonomi pada penelitian ini dikategorikan menjadi dua yaitu sosial ekonomi rendah dan sosial ekonomi tinggi. Status sosial ekonomi diukur berdasarkan besarnya pendapatan responden yang dibandingkan dengan Upah Minimum Kota/Kabupaten (UMK). Berdasarkan hasil penelitian diketahui bahwa sebagian besar status sosial ekonomi termasuk pada kategori rendah (99\%). Hal inilah yang menyebabkan secara statistik tidak terdapat hubungan antara sosial ekonomi dengan terjadinya BBLR. Berdasarkan hasil wawancara juga diketahui bahwa selama kehamilan, responden mendapatkan rajin melakukan pemeriksaan kehamilan di posyandu dan pusat-pusat pelayanan kesehatan yang terdapat disekitar rumah, serta mendapatkan vitamin dari petugas maupun kader kesehatan.

Secara teori dan rujukan penelitian sebelumnya dikatakan bahwa sosial ekonomi secara tidak langsung dapat menjadi penyebab terjadinya BBLR dimana pendapatan keluarga yang kurang akan membuat ibu kesulitan untuk mengkonsumsi makanan yang bergizi seimbang selama kehamilan. ${ }^{20}$ Ibu dengan asupan gizi yang tidak seimbang dapat menyebabkan ibu hamil mengalami anemia sehingga berpengaruh terhadap pertumbuhan dan perkembangan janin dimana bila hal ini tidak dapat diantisipasi akan meningkatkan risiko ibu untuk melahirkan bayi dengan BBLR. $^{21}$ Penjelasan tersebut menjelaskan bahwa pada penelitian ini tidak sesuai dengan teori yang ada dimana sosial ekonomi secara tidak langsung memiliki hubungan terhadap kelahiran BBLR. Penyebab terjadinya BBLR lebih banyak disebabkan karena faktor langsung yaitu faktor ibu dan janin. ${ }^{6,11}$

Aspek sosial budaya dalam penelitian ini menggali tentang pantangan-pantangan terhadap makanan minuman selama kehamilan. Keyakinan-keyakinan tentang beberapa makanan dan minuman yang perlu dipantang selama hamil berdampak terhadap perilaku makan ibu semasa hamil. Keyakinan atau kepercayaan terhadap makanan yang tidak boleh dikonsumsi selama hamil merupakan kepercayaan yang diyakini secara turun-temurun. Hasil penelitian menunjukkan bahwa terdapat beberapa makanan yang diketahui dipantang selama hamil diantaranya adalah udang, cumi, nanas. Adanya keyakinan terhadap pantangan mengkonsumsi makanan tertentu tersebut berpotensi menyebabkan terjadinya kurang gizi serta anemia pada ibu hamil. Terlebih lagi pada usia trimester pertama yang merupakan masa emas bagi kecukupan gizi bagi janin dan ibu hamil. Kekurangan gizi pada ibu 
hamil dapat berdampak terhadap terjadinya kurang energi kronis (KEK) serta anemia. Penelitian menunjukkan bahwa KEK dan anemia merupakan faktor resiko terjadinya BBLR pada bayi. ${ }^{20,22}$ Hasil penelitian Obai et al., dan Syaifaurrahmah et al., tidak sejalan dengan penelitian ini namun terdapat penelitian lain yang menyebutkan bahwa faktor sosial budaya (kebiasaan minum jamu) tidak berhubungan secara signifikan dengan kejadian BBLR. ${ }^{12}$

\section{Faktor Enabling}

Faktor enabling dalam penelitian ini terdiri dari ketersediaan pelayanan kesehatan, jarak pelayanan kesehatan, keterpaparan media promosi kesehatan. Hasil penelitian menunjukkan bahwa sebagian besar responden menyatakan bahwa pelayanan kesehatan tersedia di wilayah mereka dengan akses yang mudah dijangkau oleh moda transportasi. Rata-rata responden menggunakan sepeda motor untuk menjangkau pusat-pusat pelayanan kesehatan. Posyandu untuk ibu hamil juga tersedia disekitar wilayah responden sehingga responden tidak mengalami kesulitan dalam melakukan pemeriksaan kehamilan dengan didukung oleh peran kader dan petugas kesehatan yang baik maka upaya pencegahan kejadian BBLR dapat dicegah dan diminimalisir. Penelitian sebelumnya menyatakan bahwa dukungan dan sumber daya kesehatan yang terampil serta profesional diperlukan dalam mendukung program pelayanan kesehatan yang tentunya akan berpengaruh terhadap kesehatan masyarakat, salah satunya adalah ibu hamil dimana jarak pelayanan kesehatan, keterpaparan media promosi kesehatan menjadi salah satu cara untuk guna mencegah terjadinya komplikasi pada bayi baru lahir khususnya kejadian BBLR. Tersedianya pusat pelayanan kesehatan harus diimbangi dengan dukungan sumber daya kesehatan yang kompeten. ${ }^{23}$

Pada penelitian ini, sebagian besar responden $(97,2 \%)$ menyatakan bahwa disekitar wilayah mereka terdapat pelayanan kesehatan dengan jarak cukup dekat (kurang dari $1 \mathrm{KM}$ ) dari kediaman $(52,6 \%)$ dan $49,5 \%$ diantaranya adalah ibu yang memiliki bayi BBLR. Pusat pelayanan kesehatan yang tersebar hampir disemua wilayah mempermudah ibu hamil dalam melakukan pemeriksaan kesehatan. Pusatpusat pelayanan kesehatan yang dapat dimanfaatkan oleh ibu hamil diantaranya adalah Posyandu, Puskesmas dan Rumah Sakit. Hasil penelitian ini menunjukkan bahwa Puskesmas dan Posyandu menjadi tempat pelayanan kesehatan yang paling banyak (40\%) dikunjungi ibu hamil dalam melakukan pemeriksaan kehamilan. Pada saat ibu hamil melakukan pemeriksaan kehamilan di posyandu dan puskesmas tersebut, seluruh sampel ibu hamil, 52,9\% diantaranya adalah ibu yang memiliki bayi BBLR mendapatkan informasi dari petugas kesehatan sebagai upaya untuk menjaga kehamilan para ibu dengan baik. Informasiinformasi yang diberikan diberikan secara langsung maupun pamflet yang tepajang di fasilitas kesehatan. Ketersediaan pelayanan kesehatan, jarak pelayanan kesehatan, keterpaparan media promosi kesehatan tidak menunjukan hasil yang signifikan dengan kejadian BBLR di Puskesmas Cilegon dan Puskesmas Citangkil pada tahun 2019 dan hal ini dapat disebabkan karena faktor lain yang belum diteliti.

\section{Faktor Reinforcing}

Faktor reinforcing pada penelitian ini terdiri dari dukungan keluarga dan peran petugas kesehatan. Keluarga merupakan komponen terdekat dengan ibu hamil dalam memberikan support selama proses kehamilan dan kelahiran. Selain keluarga ada peran penting dari faktor eksternal yaitu peran tugas kesehatan. Dukungan keluarga dan peran petugas kesehatan dapat terwujud melalui keikutsertaan/keterlibatan dalam pemeriksaan kesehatan, mengingatkan dan memberikan informasi-informasi kesehatan bagi ibu hamil serta memberikan dukungan dalam mengkonsumsi makanan-minuman yang sehat dan bergizi selama kehamilan. WHO menjelaskan salah satu contoh implementasi untuk mengurangi stunting 
pada anak adalah dengan mengadakan pelayanan kesehatan berbasis komunitas dimana dibantu dan diawasi oleh tenaga kesehatan atau relawan yang terlatih dan ini dapat diterapkan di rumah, desa atau kelompok masyarakat. Hal ini bertujuan untuk mengubah kebiasaan masyarakat menjadi lebih patuh terhadap programprogram pelayanan kesehatan untuk pencegahan stunting yang secara tidak langsung stunting adalah salah satu outcome dari BBLR. Pelayanan kesehatan yang dimaksud adalah pemberian informasi pentingnya asupan asam folat, suplemen multi mikronutrien, vitamin $\mathrm{K}$, ASI eksklusif, antenatal care, perinatal care dan postnatal care. ${ }^{24}$ Pada penelitian ini tidak ada hubungan yang siginifikan antara dukungan keluarga dan peran petugas dengan bayi BBLR, hal ini dapat diakibatkan adanya multifaktor yang belum diteliti dan kendala yang terjadi saat pengambilan data.

\section{Kesimpulan}

Pada penelitian ini faktor tidak langsung yaitu predisposisi, enabling dan reinforcing tidak berhubungan secara statistik terhadap kejadian BBLR. Namun, dari penelitian ini dapat dijelaskan bahwa ketidakterpaparan media kesehatan khususnya tentang BBLR serta dukungan keluarga dan petugas kesehatan sangat diperlukan dalam mencegah terjadinya BBLR. Pada aspek sosial ekonomi rendah persentase kejadian BBLR lebih tinggi dibanding sosial ekonomi tinggi, pada responden yang tidak terpapar media kesehatan kejadian BBLR hampir setara dengan responden yang terpapar media kesehatan, persentase keluarga dan peran petugas yang tidak mendukung kejadian BBLR lebih tinggi dibanding dengan yang mendukung.

\section{Saran}

Diharapkan edukasi kesehatan ibu hamil dapat ditingkatkan melalui penggunaan media-media elektronik misal melalui grup WA, instagram dan media sosial lainnya serta memperbanyak materi tentang pencegahan BBLR pada ibu hamil pada saat melakukan penyuluhan kesehatan. Bagi penelitian selanjutnya, disarankan melakukan penelitian yang menggali lebih mendalam terkait dengan keterpaparan informasi-informasi kesehatan yang terkait dengan BBLR serta meneliti lebih jauh tentang peran petugas dan keluarga dalam mencegah kejadian BBLR.

\section{Ucapan terimakasih}

Terima kasih kepada para tenaga kesehatan dan kader di Wilayah Puskesmas Citangkil dan Puskesmas Cilegon yang turut membantu dalam proses pengumpulan data sehingga penelitian ini dapat diselesaikan tepat pada waktunya.

\section{Daftar Pustaka}

1. BKKBN. SDKI 2017 [Internet]. Survei Demografi dan Kesehatan Indonesia. 2017. Available from: https://www.un.org/sustainabledevelopment/wp content/uploads/2015/08/Factsheet_Summit.pd f

2. Kementerian Kesehatan Republik Indonesia. Profil Kesehatan Indonesia Tahun 2018 [Internet]. Vol. 40, Journal of Clinical Pathology. Jakarta: Kementerian Kesehatan Republik Indonesia; 2018. 1-556 p. Available from: http://www.kemkes.go.id

3. Kristanti M. Hubungan Bayi Berat Lahir Rendah dengan Kejadian Kematian Bayi di Kota Padang Tahun 2014 [Internet]. Padang; 2015. Available from: http://scholar.unand.ac.id/id/eprint/2939

4. Ekawaty. Jumlah Bayi Berat Lahir Rendah Masih Tinggi [Internet]. Berita UGM. 2015. Available from: https://ugm.ac.id/id/berita/10695-jumlah-bayiberat-lahir-rendah-masih-tinggi

5. Perwiraningtyas $\mathrm{P}$, Ariani NL, Anggraini CY. Analisis Faktor Resiko Tingkat Berat Bayi Lahir Rendah. Jnc. 2020;3(3):212-20.

6. Proverawati A, Ismawati C. Berat Badan Lahir Rendah. Yogjakarta: Nuhamedica; 2010.

7. Mahayana SAS, Chundrayetti E, Yulistini. Artikel Penelitian Faktor Risiko yang Berpengaruh terhadap Kejadian Berat. Jurnal.fk.unand.ac.id. 2015;4(3):664-73.

8. Kusumawati DD, Septiyaningsih R, Kania. Faktor-Faktor Ibu yang Mempengaruhi Kejadian Bayi Berat Lahir Rendah (BBLR). J Kesehat Al-Irsyad. 2016;9(2):8-16. 
9. S Husein -. Pengaruh Antenatal care terhadap kejadian Berat Bayi Lahir Rendah (BBLR). JournalUnairAcId [Internet]. 2014;3(2):160-7. Available from: http://journal.unair.ac.id/download-fullpapersbiometrik7bcfc1flbafull.pdf

10. Simamora SED, Ronoatmodjo S. Program Magister Epidemiologi, Fakultas Kesehatan Masyarakat, Universitas Indonesia 2 Departemen Epidemiologi, Fakultas Kesehatan Masyarakat, Universitas Indonesia Kampus Baru UI Depok , Jawa Barat - 16424 Indonesia. J Kesehat Reproduksi. 2020;11(1):89-100.

11. Hartiningrum I, Fitriyah N. Bayi Berat Lahir Rendah (BBLR) di Provinsi Jawa Timur Tahun 2012-2016. J Biometrika dan Kependud. 2019;7(2):97.

12. Julhana RA, Hernawan AD, Saleh I. Social Culture and Prenatal Care Factors Related To Low. Peminatan Epidemiol Kesehat Fak Ilmu Kesehat Univ Muhammadiyah Pontianak. 2014;

13. Kemenkes RI. Hasil Utama Riset Kesehatan Dasar Tahun 2018. Kementrian Kesehatan Republik Indonesia. 2018.

14. Dirjen Kesehatan Masyarakat Kemenkes RI. Rencana Aksi Program Kesehatan Masyarakat Tahun 2015-2019. 2018;1-68. Available from: http://www.kesmas.kemkes.go.id/assets/upload /dir_60248a365b4ce1e/files/RENCANAAKSI-PROGRAM-KESMAS-2015-2019-edit11-April-2018_1023.pdf

15. Dinas Kesehatan Cilegon. Profil Kesehatan Dinas Kesehatan Cilegon Tahun 2018. Cilegon; 2018.

16. Sholiha H, Sumarmi S. Analisis Risiko Kejadian Berat Bayi Lahir Rendah (Bblr) Pada Primigravida. Media Gizi Indones [Internet].
2016;10(1):57-63. Available from: https://ejournal.unair.ac.id/MGI/article/view/3127

17. Fajriana A, Buanasita A. Faktor Risiko Yang Berhubungan Dengan Kejadian Bayi Berat Lahir Rendah Di Kecamatan Semampir Surabaya. Media Gizi Indones. 2018;13(1):71.

18. Gizaw B, Gebremedhin S. Factors associated with low birthweight in North Shewa zone, Central Ethiopia: Case-control study. Ital J Pediatr. 2018;44(1):1-9.

19. Tazkiah M, Wahyuni CU, Martini S. Determinan Epidemologi Kejadian BBLR pada Daerah Endemis Malaria di Kabupaten Banjar Provinsi Kalimantan Selatan. J Berk Epidemologi. 2013;1(2):266-76.

20. Obai G, Odongo P, Wanyama R. Prevalence of anaemia and associated risk factors among pregnant women attending antenatal care in Gulu and Hoima Regional Hospitals in Uganda: A cross sectional study. BMC Pregnancy Childbirth [Internet]. 2016;16(1):1$7 . \quad$ Available from: http://dx.doi.org/10.1186/s12884-016-0865-4

21. Kozuki N, Lee AC, Katz J. Moderate to severe, but not mild, maternal anemia is associated with increased risk of small-for-gestational-age outcomes. J Nutr. 2012;142(2):358-62.

22. Syifaurrahmah $\mathrm{M}$, Yusrawati $\mathrm{Y}$, Edward $\mathrm{Z}$. Hubungan Anemia dengan Kejadian Bayi Berat Lahir Rendah pada Kehamilan Aterm di RSUD Achmad Darwis Suliki. J Kesehat Andalas. 2016;5(2):470-4.

23. Suharmiati S, Laksono A, Astuti W. UP Review Kebijakan tentang Pelayanan Kesehatan Puskesmas di Daerah Terpencil Perbatasan. Bul Penelit Sist Kesehat. 2013;16(2):109-16.

24. WHO. Reducing Stunting In Children. Equity considerations for achieving the Global Nutrition Targets 2025. 2018. 40 p. 